\title{
Оценка вертикального профиля некоторых метеорологических параметров над Майданакской астрономической обсерваторией
}

\author{
Ю.А. Тиллаев ${ }^{*}, 1$ А.В. Соловейчик ${ }^{1,2}$, Д.В. Булгакова ${ }^{1,2}$, Э.Р. Семакова ${ }^{1}$ \\ ${ }^{1}$ Астрономический институт АН РУз, ул. Астрономическая, 33, 100052, Ташкент, Узбекистан \\ ${ }^{2}$ Инфомационно-техническое управление «Meteoinfosistem» Центра гидрометеорологической службы \\ Республики Узбекистан (Узгидромет), 1-й проезд Бодомзор йули, 72, 100052, Ташкент, Узбекистан
}

Получена 26.06.2020

* Corresponding author: e-mail yusuf@astrin.uz, Phone: + +998 946311253

\begin{abstract}
В работе представлены результаты оценки высотного профиля скорости ветра и количества воды в атмосфере над астрономической обсерваторией Майданак. Распределение метеорологических величин по высоте было получено на основе географической и высотной интерполяции аэрологических метеоданных, полученных на шести станциях соседних государств. Оценки профилей метеорологических параметров атмосферы будут полезны в изучении влияния атмосферы на качество астрономических наблюдений в различные сезоны года, также как и для определения оптимальных параметров системы адаптивной оптики будущего телескопа.
\end{abstract}

\begin{abstract}
Ключевые слова: аэрологическое зондирование атмосферы, интерполяция, астрономические наблюдения, стандартные изобарические поверхности, концентрация водяного пара, скорость ветра, струйные течения, центры действия атмосферы.

The paper presents the results of an assessment of vertical profiles of wind velocity and water amount in the atmosphere over the Maidanak Astronomical Observatory. The height distributions of the meteorological quantities were obtained using geographic and altitude interpolation of aerological meteorological data of six surrounding stations of neighboring countries. The resulting profiles will be helpful in study of influence of the atmosphere to the quality of astronomical observations during different seasons as well as in determining of optimal parameters of adaptive optics of a future telescope.
\end{abstract}

Keywords: aerological sensing of the atmosphere, interpolation, astronomical observations, standard isobaric surfaces, water vapor concentration, wind speed, jet stream, atmospher action centers

\section{I. Введение и постановка задачи}

Наземные астрономические наблюдения подвержены отрицательному влиянию атмосферы, так как проводятся сквозь толщу газовой оболочки земного шара. Для учета или минимизации этого влияния необходимо знать параметры атмосферы над обсерваторией. В целом, метеопараметры в приземном слое атмосферы можно без труда измерить и изучить, потому что он находится в непос- редственной близости, и установка метеостанций и проведение измерений не составляют особых усилий. Однако суммарный негативный эффект создаётся на каждом слое атмосферы, начиная от приземного слоя до нескольких десятков километров над поверхностью. Поэтому очень важно изучить распределение метеорологических параметров в атмосфере над обсерваторией, как тот или иной параметр меняется по высоте. Таким образом, 
можно будет найти те высоты, которые наиболее негативно влияют на астрономические наблюдения. Понимание процессов, происходящих в таких слоях, позволит в дальнейшем учесть влияние атмосферы на результаты наблюдений.

В данной статье исследуются высотные профили двух параметров атмосферы над горой Майданак - скорости ветра и количества воды в атмосфере. Они представляют наибольший интерес из-за их отрицательного влияния на эффективность работы телескопов и качество астрономических наблюдений. Актуальность также возрастает в связи с полным отсутствием таких данных или наличием эпизодических измерений, которые не охватывают полный высотный профиль.

Информация о высотных профилях метеопараметров над Майданакской обсерваторией достаточно скудна. Редкие малочисленные запуски радиозондов были произведены в начале 90-х прошлого столетия. На их основании был создан приблизительный профиль скорости ветра до пограничного слоя [1,2]. В работе [3] авторы получили скорость и направление ветра на уровне 200 мб над Майданаком, используя метод пространственной интерполяции данных станций Коканд, Ташкент и Термез. Однако до 2013 г. не было ни одной работы, посвященной влагосодержанию атмосферы над горой Майданак. После установки в 2012 г. GPSстанции в обсерватории появилась возможность количественно оценить интегральное содержание воды в атмосфере [4]. В работе [5] авторы изучают скорость ветра на уровне 200 мб и количество осажденной воды на основе специального метода моделирования глобальной атмосферы.

Для изучения характеристик свободной атмосферы, в том числе температурного, влажностного и ветрового режимов, используются различные виды дистанционного зондирования: акустическое, лазерное, ракетное, самолетное, спутниковое и другие. Самым распространенным и системным видом получения метеорологической информации в верхних слоях атмосферы является метод аэрологического радиозондирования.

Аэрологические зонды предоставляют информацию о состоянии параметров атмосферы в высоких ее слоях, т.е. в удалении от подстилающей поверхности Земли, где не сказывается ее непосредственное влияние. Аэрологическое зондирование атмосферы позволяет изучить состав и вертикальное строение атмосферы Земли до больших высот, механизмы образования облаков и осадков и методы регулирования их развития, лучистый теплообмен в свободной атмосфере, воздушные течения на различных высотах, в том числе турбулентные (вихревые) движения в атмосфере, а также взаимодействие воздушных масс.

По определению Всемирной метеорологической организации (ВМО) радиозонд - это прибор, поднимаемый на газонаполненной оболочке в атмосферу, который снабжен устройствами для измерения одного или нескольких метеорологических параметров (давления, температуры, влажности и др.), а также радиопередатчиком для передачи информации о результатах измерений на станцию наблюдения $[6,7,8]$. Радиозонд может прикрепляться к газонаполненной оболочке либо может сбрасываться (сбрасываемый зонд) с воздушного судна или ракеты.

Радиозондовые системы обычно используются для измерения давления, температуры и относительной влажности. В большинстве оперативных пунктов радиозондовые системы используются также для определения ветра на высотах.

Единицами измерения метеорологических параметров при радиозондовых наблюдениях являются гектопаскаль для давления, градус Цельсия для температуры и процент для относительной влажности. Данные об относительной влажности сообщаются по отношению к давлению насыщенного пара над поверхностью воды даже при температурах ниже $0^{\circ} \mathrm{C}$.

Наблюдения при помощи радиозондов проводятся на регулярной основе для измерений вплоть до высоты около 35 км. Мировая сеть станций радиозондирования в настоящее время насчитывает более 1500 пунктов (рис. 1).

На рис. 1 зеленым цветом указаны пункты аэрологического зондирования, имеющие длительный ряд наблюдений и производящие наблюдения в мануальном режиме; красным цветом отмечены пункты наблюдения в нерегулярном режиме; сиреневым цветом выделены станции, работающие в автоматическом режиме; голубым цветом - пункты наблюдения, установленные относительно недавно (за последние 5 лет).

В настоящее время сформировано несколько глобальных архивов данных радиозондирования: RATPAC - Radiosonde atmospheric temperature products for assessing climate (NOAA), HadAT (Хэдли центр), RAOBCORE и RICH (Венский университет). Результаты аэрологических наблюдений за разные периоды времени создаются по автомати- 
зированной технологии на основе данных, поступающих в глобальные архивы данных по каналам связи из Глобальной системы телесвязи гидрометеорологических служб. Массивы организованы в виде файлов, содержанием которых являются срочные аэрологические данные по всем станциям земного шара за один месяц. В процессе создания архивных файлов аэрологические данные проходят процедуру комплексного контроля качества [9].

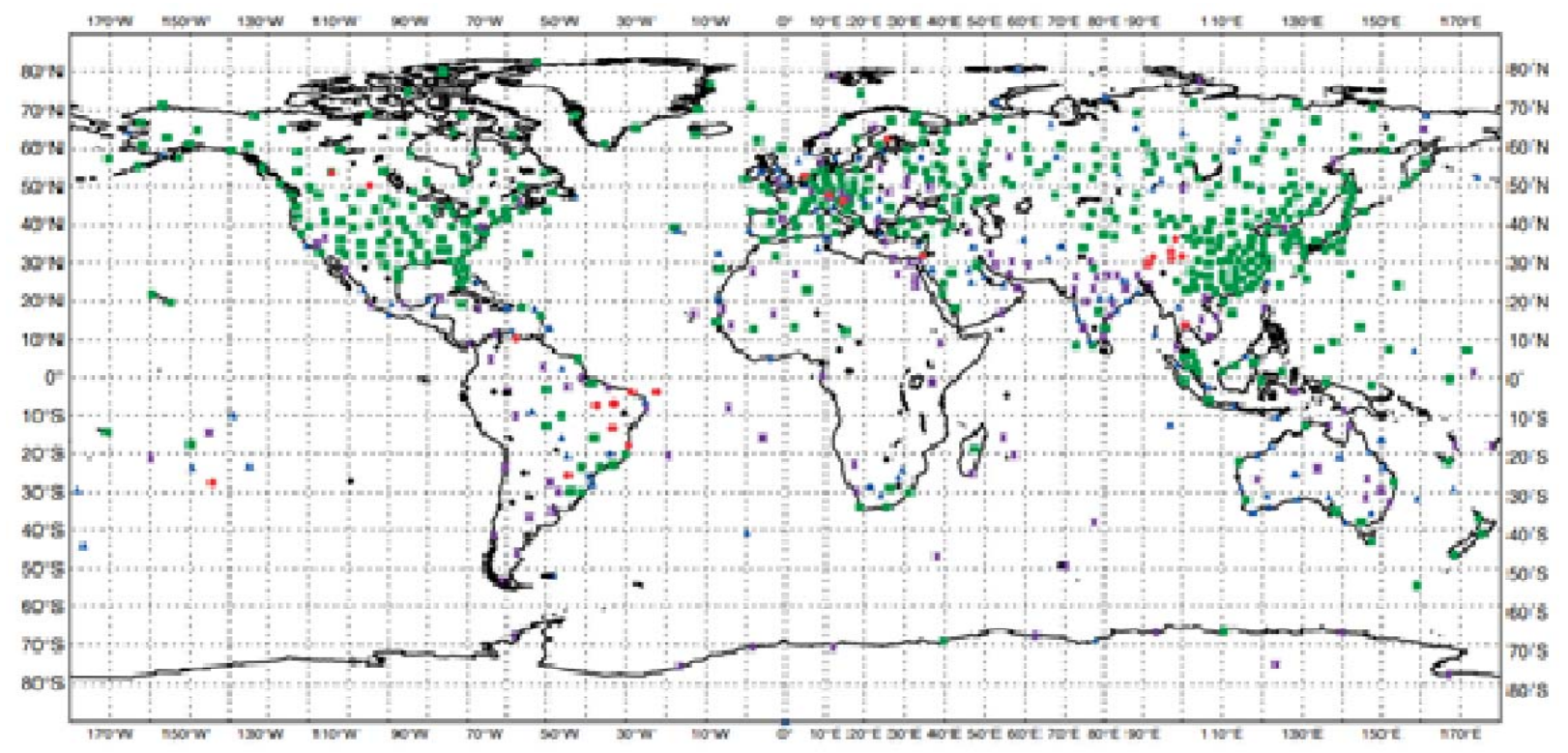

Рисунок 1. Мировая сеть станций радиозондирования.

Наблюдения с помощью свободнолетящих радиозондов проводятся в стандартные сроки: 00 и 12 часов по Гринвичу, в результате которых получают данные о вертикальном распределении температуры, влажности, геопотенциальной высоты, направлении и скорости ветра, а также о давлении воздуха. Информация включает значения метеорологических величин на стандартных изобарических уровнях и на стандартных высотах над поверхностью земли, уровнях тропопаузы и максимальной скорости ветра, а также на уровнях особых точек (резких изменений в вертикальном распределении) температуры, влажности, скорости и направления ветра. Стандартными изобарическими поверхностями считаются уровни $1000,925,850$, $700,500,400,300,250,200,150,100,70,50,30,20$, 10 гПа. Критерий выбора особых точек заключен в возможности восстановления вертикального профиля температуры с точностью до $1^{\circ} \mathrm{C}$ в тропосфере и до $2^{\circ} \mathrm{C}$ в стратосфере, профиля относительной влажности с точностью до $15 \%$ [10].

На рис. 1 видно, что сеть аэрологических наблюдений неоднородна на всем земном шаре; в районе территории Центральной Азии она сильно разрежена, что создает сложности для исследова- ния вертикального профиля атмосферы. Для решения проблемы отсутствия данных аэрологического зондирования существует практика применения метода интерполяции между ближайшими пунктами, на которых проводятся подобные наблюдения.

\section{II. Методы и материалы}

Отсутствие пунктов аэрологического зондирования в районе астрономической обсерватории Майданак с координатами $38^{\circ} 40^{\prime} 24^{\prime \prime}$ с.ш. 66 $63^{\prime} 47^{\prime \prime}$ в.д. вызвало необходимость проведения интерполяции данных, полученных с близлежащих пунктов аэрологических наблюдений. Необходимо отметить, что на территории Узбекистана аэрологические измерения прекращены в 1995 г., поэтому первая задача предстоящих исследований заключалась в определении и обосновании ближайших к астрономической обсерватории аэрологических станций, где имеется архив данных радиозондирования атмосферы с 2012 г.

Анализ географического положения ближайших станций, располагающих архивной и оперативной информацией, позволил выбрать следующие: Кызыл-Орда (Казахстан), Джамбул (Казахстан), Алматы (Казахстан), Мешхед (Иран), Кабул 
(Афганистан) (рис. 2). Все указанные географические объекты имеют продолжительный ряд метеорологических и аэрологических наблюдений, а также находятся в непосредственной географической близости к астрономической обсерватории Майданак, относительно других пунктов, производящих аэрологические наблюдения. Все выбранные объекты находятся на разной высоте от уровня моря, однако, начиная с высоты 1-2 км от уровня станции, влиянием подстилающей поверхности можно пренебречь. Таким образом, выбранные пункты отвечают заявленным требованиям.

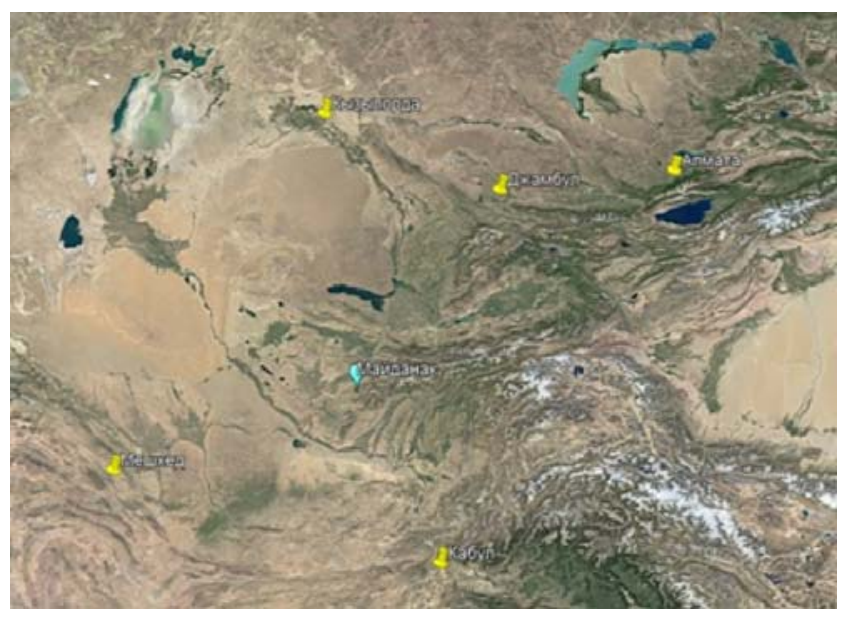

Рисунок 2. Расположение пунктов аэрологического зондирования относительно обсерватории Майданак (5 станций).

В процессе сбора архивной информации с данных станций большое внимание было уделено выбору высот, на которых будет основана последующая интерполяция данных.

Первичный анализ полученных данных выявил неоднородность данных радиозондирования по высотам. Выяснилось, что движение радиозондов неоднородно как в вертикальном разрезе атмосферы, так и во временном, т.е. высоты, на которых радиозондами фиксируется метеоинформация, отличны от срока к сроку наблюдения.

Согласно регламентам Наставления по глобальной системе обработки данных и прогнозирования ВМО [7], аэрологические наблюдения могут проводиться на любых высотах, но обязательным условием является измерение метеопараметров на стандартных изобарических высотах, для дальнейшего построения карт абсолютной барической топографии (АТ).

Карты АТ содержат сведения о высоте стан- дартной изобарической поверхности над уровнем моря и некоторых характеристиках состояния атмосферы на этой высоте. По распределению абсолютных высот той или иной изобарический поверхности можно судить о распределении давления на уровне, вблизи которого располагается данная изобарическая поверхность [9].

В результате для последующего проведения расчетов по интерполяции значений метеопараметров нами было принято решение использовать стандартные метеорологические изобарические поверхности 850, 700, 500, 400, 300, 200, 100, 50 мб, соответствующие диапазону высот от земной поверхности до 18 км (табл. 1 и [9]).

Таблица 1. Соответствие стандартных изобарических поверхностей в мб и в км.

\begin{tabular}{c|c|c}
\hline $\begin{array}{c}\text { Высота } \\
\text { пзобарической } \\
\text { поверхности, } \\
\text { мб }\end{array}$ & $\begin{array}{c}\text { Высота изоба- } \\
\text { рической } \\
\text { поверхности, } \\
\text { км }\end{array}$ & $\begin{array}{c}\text { Характеризуе- } \\
\text { мый слой } \\
\text { атмосферы, км }\end{array}$ \\
\hline 850 & 1.5 & $1-2$ \\
700 & 3.0 & $4-6$ \\
500 & 5.5 & $6-8$ \\
300 & 9.0 & $8-10$ \\
200 & 12.0 & $10-14$ \\
100 & 16.0 & $14-18$ \\
50 & 18.5 & $18-20$ \\
\hline
\end{tabular}

Следующая задача заключалась в выборе из всех имеющихся данных тех метеорологических параметров радиозондирования, которые необходимы для изучения их влияния на качество астрономических наблюдений (табл.2).

Было выявлено, что для выполнения поставленной задачи представляют интерес следующие параметры: температура воздуха, относительная влажность воздуха, концентрация водяного пара, и скорость ветра. По завершению процесса сбора и подготовки всей исходной информации, можно было приступить к непосредственному интерполированию данных для обсерватории Майданак.

\section{III. Обработка данных}

Для дальнейшей работы было разработано программное обеспечение для проведения численной интерполяции значений метеорологических параметров, представляющих интерес для данного исследования.

Принцип программы, разработанной специалистами Информационно-технического управле- 
Таблица 2. Данные аэрологического зондирования вертикального слоя атмосферы в формате .txt (Кабул, 01.11.2012 срок 00 UTC: 40948 OAKB Kabul Airport Observations at 00Z 01 Nov 2012).

\begin{tabular}{|c|c|c|c|c|c|c|c|c|c|c|}
\hline $\begin{array}{c}\text { PRES } \\
\mathrm{hPa} \\
\end{array}$ & $\begin{array}{c}\text { HGHT } \\
\mathrm{m}\end{array}$ & $\begin{array}{c}\text { TEMP } \\
\mathrm{C} \\
\end{array}$ & $\begin{array}{c}\text { DWPT } \\
\mathrm{C}\end{array}$ & $\begin{array}{c}\text { RELH } \\
\%\end{array}$ & $\begin{array}{c}\text { MIXR } \\
\mathrm{g} / \mathrm{kg}\end{array}$ & $\begin{array}{c}\text { DRCT } \\
\text { deg }\end{array}$ & $\begin{array}{c}\text { SKNT } \\
\text { knot }\end{array}$ & $\begin{array}{c}\text { THAT } \\
\mathrm{K} \\
\end{array}$ & $\begin{array}{c}\text { THTE } \\
\text { K }\end{array}$ & $\begin{array}{c}\text { THTV } \\
\mathrm{K}\end{array}$ \\
\hline $\begin{array}{l}1000 \\
925\end{array}$ & $\begin{array}{l}140 \\
826\end{array}$ & & & & & & & & & \\
\hline 850 & 1548 & & & & & & & & & \\
\hline 826 & 1791 & 10.2 & 8.3 & 88 & 8.38 & 215 & 2 & 299.3 & 324.1 & 300.8 \\
\hline 769 & 2382 & 7.6 & 1.6 & 66 & 5.62 & 196 & 2 & 302.6 & 319.8 & 303.7 \\
\hline 700 & 3147 & 1.8 & -0.7 & 83 & 5.22 & 170 & 1 & 304.4 & 320.6 & 305.4 \\
\hline 687 & 3296 & 0.6 & -1.5 & 86 & 5.02 & 0 & 0 & 304.8 & 320.4 & 305.7 \\
\hline 624 & 4063 & -5.3 & -5.5 & 98 & 4.09 & 52 & 5 & 306.5 & 319.4 & 307.2 \\
\hline 616 & 4164 & -6.3 & -7.4 & 92 & 3.58 & 59 & 5 & 306.5 & 317.8 & 307.1 \\
\hline 580 & 4634 & -8.3 & -12.6 & 71 & 2.52 & 91 & 9 & 309.4 & 317.7 & 309.9 \\
\hline 564 & 4850 & -10.3 & -12.7 & 83 & 2.57 & 106 & 10 & 309.6 & 318 & 310.1 \\
\hline 550 & 5044 & -11.3 & -18.3 & 56 & 1.65 & 119 & 11 & 310.6 & 316.2 & 310.9 \\
\hline 517 & 5517 & -13.7 & -15.4 & 87 & 2.24 & 153 & 14 & 313.3 & 320.8 & 313.7 \\
\hline 510 & 5620 & -14.5 & -16.3 & 86 & 2.11 & 160 & 15 & 313.5 & 320.6 & 313.9 \\
\hline 500 & 5770 & -15.7 & -17.6 & 85 & 1.93 & 170 & 17 & 313.8 & 320.4 & 314.2 \\
\hline 442 & 6681 & -22.4 & -23.6 & 90 & 1.3 & 190 & 24 & 316.6 & 321.1 & 316.8 \\
\hline 418 & 7093 & -25.5 & -26.3 & 93 & 1.07 & 180 & 21 & 317.7 & 321.6 & 317.9 \\
\hline 405 & 7321 & -27.5 & -30.2 & 77 & 0.77 & 175 & 20 & 318 & 320.8 & 318.2 \\
\hline 400 & 7410 & -28.3 & -31.8 & 72 & 0.67 & 175 & 20 & 318.1 & 320.6 & 318.2 \\
\hline 399 & 7428 & -28.7 & -32.6 & 69 & 0.62 & 175 & 20 & 317.8 & 320.1 & 317.9 \\
\hline 362 & 8120 & -34.1 & -36.3 & 80 & 0.48 & 194 & 24 & 319.6 & 321.4 & 319.7 \\
\hline 318 & 9016 & -42.1 & -47.1 & 58 & 0.17 & 219 & 29 & 320.5 & 321.2 & 320.6 \\
\hline 316 & 9059 & -42.5 & -47.3 & 59 & 0.17 & 220 & 29 & 320.6 & 321.2 & 320.6 \\
\hline 315 & 9080 & -42.7 & -47.4 & 60 & 0.17 & 221 & 30 & 320.6 & 321.2 & 320.6 \\
\hline 300 & 9410 & -43.9 & -56.9 & 22 & 0.06 & 240 & 43 & 323.4 & 323.6 & 323.4 \\
\hline 297 & 9477 & -44.3 & -59.3 & 17 & 0.04 & 244 & 46 & 323.7 & 323.9 & 323.8 \\
\hline 292 & 9591 & -44.5 & -62.5 & 12 & 0.03 & 250 & 50 & 325.1 & 325.2 & 325.1 \\
\hline 284 & 9777 & -44.7 & -67.7 & 6 & 0.01 & 252 & 54 & 327.3 & 327.4 & 327.3 \\
\hline 253 & 10541 & -49.2 & -67.7 & 10 & 0.02 & 260 & 69 & 331.6 & 331.7 & 331.6 \\
\hline 250 & 10620 & -49.7 & -67.7 & 10 & 0.02 & 260 & 69 & 332.1 & 332.1 & 332.1 \\
\hline 238 & 10941 & -51.7 & -69.7 & 10 & 0.01 & 257 & 63 & 333.7 & 333.8 & 333.7 \\
\hline 228 & 11220 & -51.8 & -72.2 & 7 & 0.01 & 255 & 58 & 337.8 & 337.8 & 337.8 \\
\hline 207 & 11848 & -51.9 & -77.9 & 3 & 0 & 251 & 65 & 347 & 347 & 347 \\
\hline 200 & 12070 & -53.7 & -78.7 & 3 & 0 & 250 & 68 & 347.6 & 347.6 & 347.6 \\
\hline 196 & 12199 & -54.5 & -79.3 & 3 & 0 & 250 & 70 & 348.3 & 348.3 & 348.3 \\
\hline 185 & 12566 & -56.9 & -80.9 & 3 & 0 & 246 & 67 & 350.2 & 350.2 & 350.2 \\
\hline 171 & 13059 & -58.4 & -82 & 3 & 0 & 240 & 62 & 355.7 & 355.7 & 355.7 \\
\hline 157 & 13594 & -60 & -83.2 & 3 & 0 & 255 & 47 & 361.7 & 361.7 & 361.7 \\
\hline 150 & 13880 & -60.9 & -83.9 & 3 & 0 & 245 & 44 & 365 & 365 & 365 \\
\hline 140 & 14304 & -62.7 & -84.7 & 4 & 0 & 245 & 40 & 369.1 & 369.1 & 369.1 \\
\hline 131 & 14713 & -64.4 & -85.5 & 4 & 0 & 255 & 55 & 373 & 373.1 & 373 \\
\hline 122 & 15150 & -66.3 & -86.3 & 5 & 0 & 240 & 50 & 377.3 & 377.3 & 377.3 \\
\hline 100 & 16370 & -61.7 & -87.7 & 2 & 0 & 260 & 35 & 408.2 & 408.3 & 408.2 \\
\hline 92 & 16880 & -63.3 & -88.7 & 2 & 0 & 255 & 17 & 415 & 415 & 415 \\
\hline
\end{tabular}


ния «Метеоинфосистем» Узгидромета, представляет собой скомплексированный алгоритм, состоящий из нескольких методов интерполяции, применяемых в геоинформационных системах для моделирования поверхностей и решения пространственных задач.

Основными методами интерполяции, использованными в алгоритме программы, являются метод ближайшего соседа, линейная интерполяция, триангуляция Делоне, полином Лагранжа на системе равноотстоящих интерполяционных узлов. Основное назначение интерполяции - это вычисление значений табулированной функции для неузловых (промежуточных) значений аргумента [14]. Выбор указанных методов интерполяции подобран для наиболее эффективного решения поставленной задачи, сложность в решении которой состоит в соблюдении ряда условий.

Эти условия обусловлены различными высотами расположения пунктов наблюдения и орографии местности $[10,12,14]$. В этом случае перед проведением интерполяции необходимо определить те узлы интерполяции, для которых справедливо условие расположения всех имеющихся массивов данных на одинаковой высоте относительно уровня моря. При этом обязательным требованием является расположение искомого пункта наблюдения в центре области интерполяции. Таким образом, достигается наименьшая погрешность интерполяции $[11,12,13]$.

Поскольку методика для проведения интерполяции широко применяется в геоинформационных системах Узгидромета, показатели успешности проведения интерполяции являются довольно высокими. В связи с отсутствием на территории Узбекистана аэрологических наблюдений к точности проводимой интерполяции предъявляются высокие требования. Таким образом, для оценки точности методики интерполяции, проводимой в нашем исследовании, для всех выбранных нами пунктов аэрологического зондирования были проведены синтетические тесты путем выбора для каждого из них диапазона объектов, при условии, что искомый пункт будет находиться в центре триангуляционного поля, а также сравнения результатов интерполяции с реальными результатами аэрологического зондирования над заданным пунктом. Точность полученных результатов составляет $87-90 \%$ для тропосферы и $80-85 \%$ для стратосферы. Определяющим фактором точности применяемой методики является почти полная идентичность интерполированных и реальных данных в приземном слое - до 92-95\%.

Проведение тестовых расчетов исследуемых метеопараметров над обсерваторией Майданак выявило низкие показатели верности полученных результатов. Было обнаружено несколько важных критериев, которые привели к низким показателям достоверности полученных результатов. Выяснилось, что в собранном архиве в пунктах зондирования отсутствуют длительные периоды аэрологических наблюдений на некоторых станциях. В связи с тем, что для получения значений метеопараметров на Майданаке было выбрано ограниченное число относительно близких по географическому расположению пунктов наблюдения, отсутствие хотя бы одного из них приводило к сильному искажению полученного результата. Таким образом, для повышения качества дальнейшей интерполяции было принято решение о необходимости введения дополнительного, шестого, пункта аэрологического зондирования станции Каши (Китай) (рис. 3).

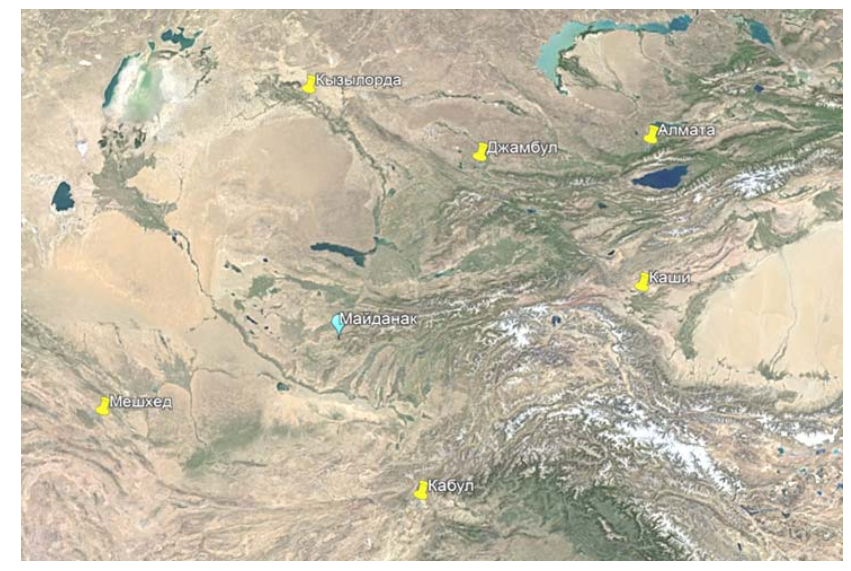

Рисунок 3. Расположение пунктов аэрологического зондирования относительно обсерватории Майданак (6 станций).

Географическое расположение аэрологической станции Каши (Китай) таково, что она находится на некотором удалении от объекта исследования, чем другие выбранные пункты, однако это не повлияло на результат исследования в пространственном разрешении. Более того, это благоприятным образом сказалось на применении алгоритмов интерполяции в линейном приближении, а также на применении квадратичной триангуляции в системе равноотстоящих интерполяци- 
онных узлов. Таким образом, введение дополнительного пункта аэрологического зондирования в решение поставленной задачи значительно улучшило итоговую картину в пространственном разрешении.

Анализ полученной архивной информации показал неоднородность рядов в вертикальном слое атмосферы (данные на некоторых стандартных изобарических поверхностях отсутствуют), но имеются данные наблюдений на близлежащих к ним поверхностях, характеризующих слой атмосферы на указанной высоте, однако не усваиваются программным обеспечением, используемым для проведения исследования. В результате этого образуются так называемые «вертикальные пробелы» в рядах данных, что сильно влияет на качество результата проводимого исследования. В связи с выбором в исследовании жесткой сетки вертикального слоя атмосферы, привязанного к стандартным изобарическим поверхностям, было принято решение о необходимости проведения интерполяции по восполнению рядов отсутствующих значений на стандартных изобарических поверхностях в вертикальном разрезе атмосферы.

В результате, программное обеспечение для проводимой интерполяции было адаптировано к проведению интерполяции в двух направлениях пространственном для пункта наблюдения Майданак и высотном для получения наиболее полного ряда значений необходимых метеорологических параметров. Для оценки точности проведенной интерполяции для Майданака было проведено сравнение интерполированных данных в приземном слое с реальными данными, полученными в результате наземных наблюдений. Точность составила $93 \%$.

С завершением проведенных операций был получен массив значений (более 270000 ) метеорологических элементов в вертикальном слое атмосферы для астрономического пункта наблюдения на горе Майданак - ежедневные данные за два срока наблюдения (00 и 12 UTC) по 5-ти метеорологическим элементам за период с ноября 2012 по октябрь 2019 года.

\section{IV. Результаты и обсуждение}

Полученный массив данных был использован для дальнейшей оценки метеорологических параметров в высоких слоях атмосферы и их возможного влияния на качество астрономических наблюдений над Майданаком. Определяющими па- раметрами были выбраны концентрация водяного пара и скорость ветра в вертикальном слое атмосферы.

Для наиболее полной метеорологической характеристики определяющих параметров состояния атмосферы было решено разделить полученный массив данных на два периода года - теплый и холодный. В холодный период вошли данные с января по апрель и с ноября по декабрь, а в теплый - с мая по октябрь включительно.

Анализируя полученные данные (табл. 3 и рис. 4), было отмечено, что в теплый период года численные значения концентрации водяного пара преобладают в интервале от 1 до 11.5 г/кг в приземном слое $(850$ мб) и начинают интенсивно убывать в слое от 700 мб по всей толще атмосферы. На высоте 50 мб в основном преобладают значения концентрации водяного пара в интервале $0-0.7$ г/кг.

Таблица 3. Распределение значений концентрации водяного пара по стандартным изобарическим поверхностям в теплый период года.

\begin{tabular}{c|c|c|c}
\hline $\begin{array}{c}\text { Высота } \\
\text { порхности, }\end{array}$ & $\begin{array}{c}\text { Концентра- } \\
\text { ция водяно- } \\
\text { го пара г/кг, } \\
\text { мин. знач. }\end{array}$ & $\begin{array}{c}\text { Концентра- } \\
\text { ция водяно- } \\
\text { го пара г/кг, } \\
\text { медиана }\end{array}$ & $\begin{array}{c}\text { Концентра- } \\
\text { ция водяного } \\
\text { пара, г/кг, } \\
\text { макс. знач. }\end{array}$ \\
\hline 850 & 1.0 & 5.1 & 11.5 \\
700 & 0.6 & 3.7 & 8.8 \\
500 & 0.6 & 1.8 & 3.7 \\
300 & 0.4 & 1.4 & 2.0 \\
200 & 0.2 & 0.8 & 1.8 \\
100 & 0.1 & 0.3 & 1.1. \\
50 & 0 & 0.1 & 0.7 \\
\hline
\end{tabular}

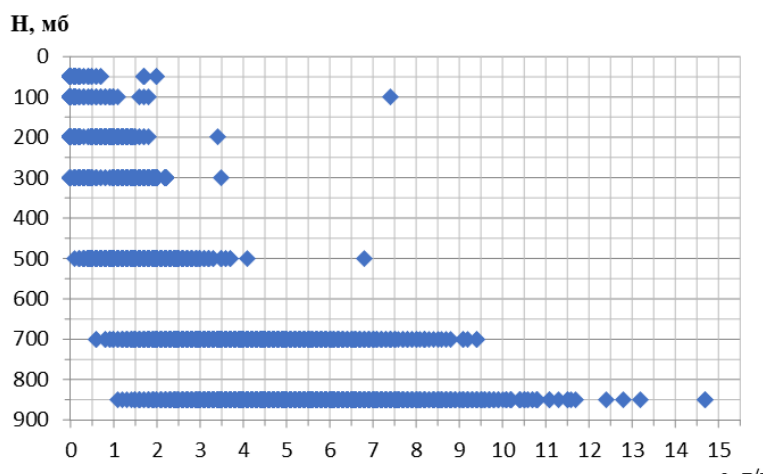

e, $\mathbf{\Gamma} / \mathbf{K} \Gamma$

Рисунок 4. Изменение концентрации водяного пара с высотой в теплый период года.

В холодный период года значения концентрации водяного пара, аналогично теплому сезону 
года, также плавно изменяются с увеличением высоты от интервала 0.5 до 7.5 г/кг в приземном слое на высоте 850 мб до интервала 0-1.7 г/кг на высоте 50 мб (табл. 4 и рис. 5).

Таблица 4. Распределение значений концентрации водяного пара по стандартным изобарическим поверхностям в холодный период года.

\begin{tabular}{c|cc|c}
\hline $\begin{array}{c}\text { Высота } \\
\text { Морхност, } \\
\text { Мб }\end{array}$ & $\begin{array}{c}\text { Концентрация } \\
\text { водяного пара } \\
\text { Гг, мин. знач. }\end{array}$ & $\begin{array}{c}\text { Концентра- } \\
\text { ция водяного } \\
\text { пара, г/кг, } \\
\text { медиана }\end{array}$ & $\begin{array}{c}\text { Концентрация } \\
\text { водяного пара } \\
\text { г/кг, макс. } \\
\text { знач. }\end{array}$ \\
\hline 850 & 0.5 & 2.8 & 7.5 \\
700 & 0.3 & 1.9 & 5.5 \\
500 & 0.2 & 1.9 & 3.5 \\
300 & 0.2 & 0.1 & 3.2 \\
200 & 0.1 & 1.4 & 2.5 \\
100 & 0 & 0.1 & 2.0 \\
50 & 0 & 0.03 & 1.7 \\
\hline
\end{tabular}

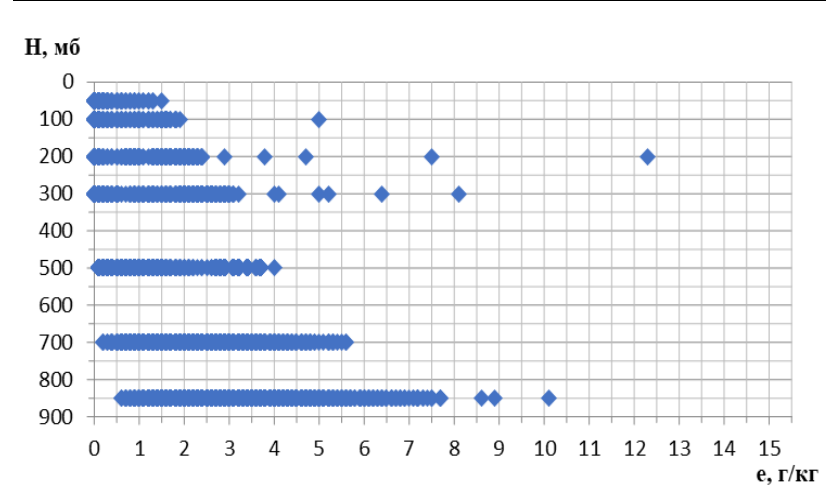

Рисунок 5. Изменение концентрации водяного пара с высотой в холодный период года.

Сравнительный анализ концентрации водяного пара между теплым и холодным полугодием показал, что в верхних слоях тропосферы и нижних слоях стратосферы (8-20 км) значения параметра в теплый период года минимальны, что говорит об отсутствии влияния количества водяного пара на «чистоту» и прозрачность атмосферы.

В холодный же период года отмечается незначительное увеличение модульных значений данного параметра в высоких слоях атмосферы. Это является свидетельством того, что частицы водяного пара в слое атмосферы могут влиять на прозрачность атмосферы.

Анализ значений скорости ветра в теплый период года (табл. 5 и рис. 6) показал, что численные значения указанного параметра преобладают в интервале $2.1-16.8$ м/с в приземном слое и плавно возрастают до слоя 500 мб. В слое от 300 до 100 мб происходит резкое увеличение модульных значений скорости ветра до 4.2-50.7 м/с. В слое выше поверхности 100 мб скорость ветра резко уменьшается до интервала 1.7-22.4 м/с.

Таблица 5. Распределение значений скорости ветра по стандартным изобарическим поверхностям в теплый период года.

\begin{tabular}{c|c|c|c}
\hline $\begin{array}{c}\text { Высота } \\
\text { поверхности, } \\
\text { Мб }\end{array}$ & $\begin{array}{c}\text { Скорость } \\
\text { ветра, м/с, } \\
\text { мин. знач. }\end{array}$ & $\begin{array}{c}\text { Скорость } \\
\text { ветра, м/с, } \\
\text { медиана }\end{array}$ & $\begin{array}{c}\text { Скорость } \\
\text { ветра, м/с, } \\
\text { макс. 3нач. }\end{array}$ \\
\hline 850 & 2.1 & 6.1 & 16.8 \\
700 & 2.3 & 6.8 & 19.2 \\
500 & 2.3 & 11.1 & 28.6 \\
300 & 4.2 & 19.7 & 43.2 \\
200 & 5.4 & 26.2 & 50.7 \\
100 & 6.1 & 17.5 & 45.9 \\
50 & 1.7 & 7.3 & 22.4 \\
\hline
\end{tabular}

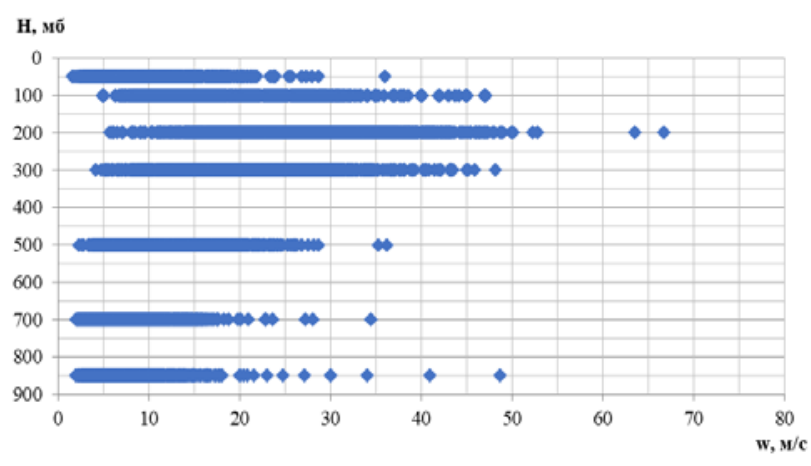

Рисунок 6. Изменение скорости ветра с высотой в теплый период года.

Значения скорости ветра в холодный период года (табл. 6 и рис. 7), аналогично теплому полугодию, преобладают в интервале $2.3-22.4$ м/с в приземном слое и плавно возрастают до высоты 500 мб до значений $4.8-57.2 \mathrm{~m} / \mathrm{c}$. В слое $300-100$ мб резко возрастают до 5.1-70.5 м/с, и снова убывают до значений 1.3-40.4 м/с на высоте 50 мб.

Анализ сезонных изменений скорости ветра показал, что увеличение модульных значений до $70 \mathrm{~m} / \mathrm{c}$ в холодный период года является свидетельством струйных течений в слое верхней тропосферы и нижней стратосферы.

По определению ВМО струйное течение это сильный узкий поток с почти горизонтальной осью в верхней тропосфере или нижней стратосфере, характеризующийся большими вертикаль- 
ными и горизонтальными сдвигами ветра и одним или более максимумами скорости [7].

Таблица 6. Распределение значений скорости ветра по стандартным изобарическим поверхностям в холодный период года.

\begin{tabular}{c|c|c|c}
\hline $\begin{array}{c}\text { Высота } \\
\text { поверхности, } \\
\text { Мб }\end{array}$ & $\begin{array}{c}\text { Скорость вет- } \\
\text { ра, м/с, мин. } \\
\text { знач. }\end{array}$ & $\begin{array}{c}\text { Скорость вет- } \\
\text { ра, м/с, ме- } \\
\text { диана }\end{array}$ & $\begin{array}{c}\text { Скорость вет- } \\
\text { ра, м/с, макс. } \\
\text { знач. }\end{array}$ \\
\hline 850 & 2.3 & 6.1 & 22.4 \\
700 & 2.3 & 7.9 & 23.7 \\
500 & 4.1 & 14.6 & 35.1 \\
300 & 4.8 & 31.4 & 57.2 \\
200 & 5.1 & 37.8 & 70.3 \\
100 & 7.5 & 29.8 & 52.1 \\
50 & 1.3 & 17.4 & 40.4 \\
\hline
\end{tabular}

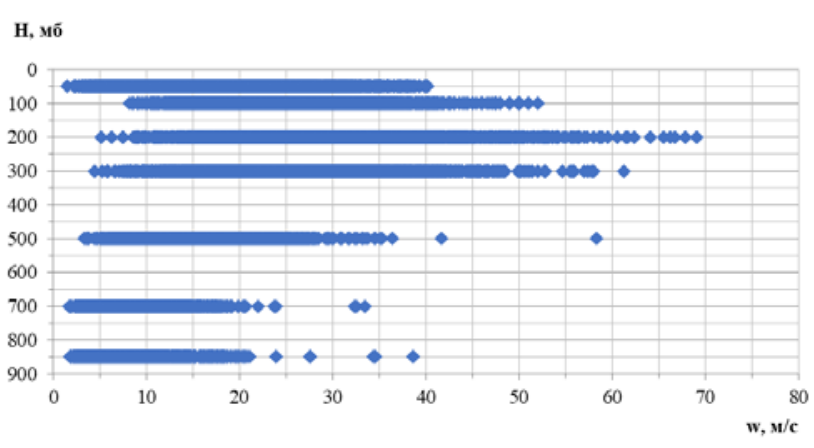

Рисунок 7. Изменение скорости ветра с высотой в холодный период года.

Длина струйного течения порядка тысяч километров, ширина - сотен километров, вертикальная мощность - нескольких километров. Условно за нижний предел струйного течения принимаются скорости 25 м/с $[15,16]$. В струйныХ течениях сконцентрирована максимальная кинетическая энергия атмосферы. В тропосфере они чаще возникают, усиливаются и разрушаются в северной и средней части умеренной зоны и в субтропиках. Струйные течения в тропосфере имеют преимущественно западное направление.

Стратосферные струйные течения зимой имеют западное, а летом восточное направление. Тропосферные, как и стратосферные, струйные течения, возникают во фронтальных зонах между областями высокого и низкого давления. Они являются наиболее подвижными, а интенсивность их непрерывно изменяется в связи с возникновением и развитием циклонов и антициклонов. Ось струи располагается чаще всего на уровне $7-10$ км зимой и 9-12 км летом $[15,16,19]$.
Положение струйных течений совпадает с положением области наиболее сильных меридиональных градиентов температуры и давления в тропосфере, т.е. с положением высотной фронтальной зоны. Струйные течения умеренных широт связаны с главными фронтами тропосферы полярными и арктическими $[18,19]$.

Сезонные различия выражаются главным образом в интенсивности и широтном положении южных (субтропических) струй. В связи с большими контрастами температур между низкими и высокими широтами скорости ветра в струе в холодное время года больше, чем летом, причем максимальные скорости отмечаются на более низких уровнях. В теплое время года скорости ветра меньше, а максимальные скорости наблюдаются на более высоких уровнях, чем зимой [15, $16,17]$. Такое проявление струйных течений связано с общей циркуляцией атмосферы и влиянием на географическое положение горы Майданак сезонных центров действия атмосферы - Сибирского (азиатского) зимнего максимума с центром над Монгольским плато и Азиатским летним минимумом (южно-азиатская, передне-азиатская летняя депрессия) с центром над Афганистаном [16, $17,19]$. Сибирский зимний максимум (антициклон) с центром над Монгольским плато - это обширная область высокого давления, которая находится над Центральной Азией и Сибирью.

В виде самостоятельного барического центра отмечается в период с сентября по май, и, формируясь под влиянием циркуляционных условий, одновременно испытывает значительное термическое воздействие материка, а также влияние горных систем Восточной и Центральной Азии. Горные системы способствуют задержанию и накоплению холодных воздушных масс $[16,17,18]$.

Азиатский летний минимум представляет собой частный случай экваториальной депрессии $[15,16,18]$. Экваториальная депрессия - полоса пониженного атмосферного давления, охватывающая земной шар вблизи экватора. Экваториальная депрессия не совпадает с географическим экватором и смещается от экватора в зависимости от сезона то к северу, то к югу в то полушарие, где в данное время лето. В экваториальной депрессии располагается внутритропическая зона конвергенции. Зона конвергенции - переходная зона между барическими центрами северного и южного полушарий. Она характеризуется конвергенцией скорости, т. е. ослаблением скорости вет- 
ра и сходимостью линий тока, а также уменьшением численных значений других метеорологических характеристик в слое атмосферы.

Исследование метеопараметров, полученных для пункта астрономической обсерватории на горе Майданак, показало, что описанные выше центры действия атмосферы благоприятным образом влияют на качество проводимых астрономических наблюдений в теплый период года. В холодный же период года исследуемые метеорологические параметры имеют более высокие, по сравнению с теплым периодом года, значения, что вызывает затруднения в проведении астрономических исследований на Майданаке.

Дальнейшие работы будут связаны с интегрированием величины концентрации водяного пара по всей толще атмосферы в целях сравнения ее с величиной осажденной воды, используемой в астрономических исследованиях, и выявлением связи с оценками количества воды, полученными с использованием GPS-приемников. Это позволит впоследствии проводить сравнения с условиями атмосферы на других астрономических обсерваториях.

\section{V. Заключение}

Впервые были получены оценки высотного профиля скорости ветра над астрономической обсерваторией Майданак продолжительностью в несколько лет. Анализ этих данных показал умеренное движение воздушных масс над Майданаком и полностью согласуется с соответствующими выводами в литературе [1]. Также впервые было получено распределение количества воды по высоте над данной обсерваторией. Проанализировано поведение скорости ветра и концентрации водяного пара в атмосфере за теплый и холодный периоды года. Для этого в процессе работы были получены следующие результаты.

1) Определены пункты аэрологического зондирования, расположенные на относительном удалении от астрономической обсерватории, для получения данных аэрологического зондирования над обсерваторией Майданак.

2) Обоснованы высоты для проведения интерполяции и получения рядов метеорологических параметров для дальнейшего анализа.

3) Разработано программное обеспечение для проведения численной интерполяции значений метеорологических параметров как в пространственном, так и в высотном направлениях.
4) Произведена интерполяция, выполнен анализ результатов, сформулированы выводы по полученным результатам.

5) Научно обосновано влияние основных центров действия атмосферы на результаты проведенного исследования и соответствующие выводы об уникальности астроклимата на Майданакской обсерватории.

Результаты проведенного анализа метеорологических параметров в теплый и холодный периоды года за исследуемый период для пункта астрономической обсерватории на горе Майданак показали уникальность астроклимата данной обсерватории, обусловленной благоприятным физико-географическим ее расположением. В теплый период года территория находится под влиянием зоны конвергенции азиатской депрессии, что объясняет незначительные величины метеорологических параметров, способных повлиять на прозрачность атмосферы. В холодный же период года на эту территорию оказывает влияние южная периферия сибирского антициклона, что обуславливает высокие показатели исследуемых метеорологических величин и объясняет периодические затруднения в проведении астрономических наблюдений.

Благодарности. Работа выполнена в рамках Гос. проекта прикладных исследований № ФААтех-2018-392 по теме: «Исследование астроклимата горы Майданак с целью оптимизации программ наблюдений для 4-х метрового адаптивного телескопа». Авторы выражают благодарность директору НИГМИ Узгидромета, д.г.н. (DSc) Холматжанову Б.М. за полезные советы и оказанную помощь при подготовке статьи, а также рецензентам данной работы, ценные замечания которых, несомненно, улучшили ее качество.

\section{Метаданные}

An assessment of vertical profiles of some meteorological parameters over Maidanak Astronomical Observatory

\section{Ю.А. Тиллаев, ${ }^{1}$ А.В. Соловейчик ${ }^{1,2}$, Д.В. Булга-} кова $^{1,2}$, Э.Р. Семакова ${ }^{1}$

${ }^{1}$ Ulugh Beg Astronomical Institute of the Uzbek Academy of Sciences, Astronomicheskaya 33, 100052 Tashkent, Uzbekistan

${ }^{2}$ Meteoinfosistem of Uzgidromet, 1-st passage Bodomzor yuli, 72, 100052, Tashkent, Uzbekistan

The paper presents the results of an assessment of vertical profiles of wind velocity and water amount in the atmos- 
phere over the Maidanak Astronomical Observatory. The height distributions of the meteorological quantities were obtained using geographic and altitude interpolation of aerological meteorological data of six surrounding stations of neighboring countries. The resulting profiles will be helpful in study of influence of the atmosphere to the quality of astronomical observations during different seasons as well as in determining of optimal parameters of adaptive optics of a future telescope.

Keywords: aerological sensing of the atmosphere, interpolation, astronomical observations, standard isobaric surfaces, water vapor concentration, wind speed, jet stream, atmospher action centers

\section{Литература (References)}

[1] S.A. Ehgamberdiev, A.K. Baijumanov, S.P. Ilyasov, M. Sarazin, Y.A. Tillayev, A.A. Tokovinin, A. Ziad. The astroclimate of Maidanak Observatory in Uzbekistan, Astron. Astrophys. Suppl. Ser. 145, 293-304 (2000).

[2] S. Ilyasov and Y. Tillayev. The atmospheric conditions of the Maidanak Observatory in Uzbekistan for ground-based observations. In Proc. SPIE 7651, International Conference on Space Information Technology 2009, 76511N, 2 April 2010. doi: $10.1117 / 12.855562$

[3] S. Ilyasov, Y. Tillayev, Sh. Ehgamberdiev. On the high altitude wind speed above the Mount Maidanak, In Proc. SPIE 4341, 181-184 (2000b).

[4] Y. Rajabov,Y. Tillayev. Maidanak observatoriyasi atmospherasidagi integral suv bugi mikdori variaciyalarini urganish [Study of variations in the amount of integral water vapor in the atmosphere of the Maidanak Observatory], In "Mesto I rol Mirzo Ulughbeka v razvitii mirovoy civilizacii”, (Tashkent, Uzbekistan), 28 March 2019, p. 443-444.

[5] J.A. Hellemeier, R. Yang, M. Sarazin, P. Hickson. Weather at selected astronomical sites - an overview of five atmospheric parameters. Monthly Notices of the Royal Astronomical Society 482, Issue 4, 4941-4950 (2019); https://doi.org/10.1093/mnras/sty2982.

[6] World Meteorological Organization, International Meteorological Vocabulary, Geneva: Second edition, WMO-No 182, (1992).

[7] World Meteorological Organization, Manual on the Global Observing System I, Geneva: WMO-No 544, (2003a).

[8] Rukovodstvo WMO po meteorologicheskim priboram i metodam nablyudeniy, [WMO Guide to Meteorological Instruments and Methods of Observation], https://library.wmo.int/pmb_ged/wmo_8-2014_ru.pdf. (In Russian).

[9] G.D. Zubyan, Sinoptiko-aerologicheskie issledovaniya verhney troposferi i nigney stratosferi (Moscow, 1961, p. 53-71). (In Russian).

[10] N.A. Zaytceva. Aerologiya. (Gidrometeoizdat, 1990, 325 p.) (In Russian).

[11] S.E. Miheev, Mnogomernaya approksimaciya i interpolyaciya (S-Pb: S-Pb University, 2012, p. 59-72) (In Russian).

[12] G.M. Fihtengolz. Kurs differencialnogo i integralnogo ischisleniya. Vol. 3 (Moscow, 1977, p. 217-228) (In Russian).
[13] B.P. Demidovich, I.A. Maron. Osnovi vichislitelnoy matematiki (Moskow, Nauka, 1966) (In Russian).

[14] A.V. Skvorcov, Y.L. Kostyuk. Effektivnie algoritmi postroeniya triangulyacii Delone. Geoinformatika. Teoriya i practika. Vol. 1 (Tomsk: Tomsk University, 1998, p. 22-47). (In Russian).

[15] M.V. Burkova, V.A. Djordgio. Vertikalnie profili vetra kak sredstvo analiza struinih techeniy (Tashkent, TashGU Proc. 259, 1964). (In Russian).

[16] V.A. Djordgio. Struinie techeniya. Obzor zarubegnoy literaturi 12/13, 1956). (In Russian).

[17] S.I. Inogamova, T.M. Muhtarov, Sh.T. Muhtarov. Osobennosti sinopticheskih processov Sredney Azii (Tashkent, 2002, p. 412-439). (In Russian).

[18] L.T. Matveev. Kurs obschey meteorologii i fiziki atmosferi, (L.: Gidrometeoizdat, 2000, p. 778-811). (In Russian).

[19] P.W. Thorne, J.R. Lanzante, T.C. Peterson, D.J. Seidel and K.P. Shine. Tropospheric temperature trends: history of an ongoing controversy. Climate Change 2, No.1 (2010).

Баъзи метеорологик параметрларнинг Майданак астрономик обсерваторияси юқорисидаги вертикал профилини бахолаш

\author{
Ю.А. Тиллаев ${ }^{1 *}$, А.В. Соловейчик ${ }^{1,2}$, Д.В. Булга- \\ кова ${ }^{1,2}$, Э.Р. Семакова ${ }^{1}$
}

${ }^{1} \breve{У ̆}_{3}$ ФА Астрономия институти, Астрономия кўч, 33

уй, 100052, Тошкент, Ўзбекистон

${ }_{2}^{2} \breve{y}_{3}$ Р Гидрометеорология хизмати маркази

(Ўзгидромет) «Meteoinfosistem» ахборот-техник

бошқармаси, Бодомзор йўли, 1 тор кўча 72 уй, 100052 ,

Тошкент, Ўзбекистон

Бу ишда Майданак астрономик обсерваторияси юқорисидаги атмосферадаги шамол тезлиги ва сув микдорининг баландлик профилини бахолаш буйича олинган натижалар келтирилган. Метеорологик катталикларнинг вертикал тақсимоти кўшни мамлакатларда жойлашган олтита станция маълумотларини географик и баландлик бўйича интерполяция қилиш орқали олинган. Метеорологик параметрларнинг профиллари атмосферанинг хар-хил мавсумдаги астрономик кузатувларга таъсирини ўрганишда, хамда ўрнатилиши мўлжалланган телескоп адаптив тизими оптимал параметрларини аниқлашда асқотади.

Калит сўзлар: атмосферани аэрологик зондлаш, интерполяция, астрономик кузатувлар, стандарт изобарик юзалар, сув буғи концентрацияси, шамол тезлиги, ингичка оқимлар, атмосфера таъсир марказлари. 